\title{
The characteristics and dynamics of management controls in IJVs: Evidence from a Sino-Japanese case
}

\author{
Pingli $\mathrm{Li}^{\mathrm{a}, *}$, Guliang Tang ${ }^{\mathrm{b}}$, Hiroshi Okano ${ }^{\mathrm{c}}$, Chen Gao ${ }^{\mathrm{d}}$ \\ a Middlesex University Business School, UK \\ b University of International Business and Economics, PR China \\ c Osaka City University, Japan \\ d Beijing Technology and Business University, PR China
}

\section{A R T I C L E I N F O}

\section{Keywords:}

Management controls

International joint venture

Dynamics

Multiple-dimensions

China

\begin{abstract}
A B S T R A C T
This paper examines the characteristics and dynamics of management controls in international joint ventures (IJVs) from multiple-dimensional perspectives. Adopting an in-depth case study method in the instance of a large automotive IJV formed between two Chinese and Japanese partners, the study seeks to improve on existing models by accounting for the three dimensions of management controls: mechanism, focus, and extent, and examining their interrelationships and dynamics. It offers the first observation on how, at the post-formation stage, parents may adjust the extent of control over specific activities or the tightness of a control mechanism to reflect environmental changes without unsettling their overall control structure; thus, a balance between stability and change is achieved. A shared but split control style is identified, supplementing previous descriptions of management style in IJVs, within which two partners share control access over the entire range of activities with broad control focus, but each possesses tight control only over certain specific activities.
\end{abstract}

(C) 2013 Elsevier Ltd. All rights reserved.

\section{Introduction}

This study investigates the characteristics and dynamics of management controls in international joint ventures (IJVs). An in-depth case study method is used to examine a large automotive IJV formed between two Chinese and Japanese partners. By providing detailed explanations unlikely to be found by using survey methods, we offer an in-depth understanding not only of what, but also of how, management controls have been exercised and evolved in the case company at post-formation stage. While previous studies have taken a static view, focusing on one or two dimensions of management controls, we seek to improve

\footnotetext{
* Corresponding author at: Middlesex University Business School, The Burroughs, Hendon, London NW4 4BT, UK. Tel.: +44 208411 5738; fax: +44020 84114739 .

E-mail address: p.li@mdx.ac.uk (P. Li).
}

on existing models by accounting for the three dimensions: mechanism, focus, and extent, and examining their interrelationships and dynamics.

Over time, IJVs have become common in a wide range of industries, due to rapid technological changes and increased emphasis on globalisation strategies (Glaister and Buckley, 1994). China, as a large growing economy with increasing international influence and a rapidly growing domestic market, is becoming more and more attractive to investors. IJV between overseas companies and Chinese firms has been one of the main modes of entry into China $^{1}$ (Xia et al., 2008). In the automotive industry, in fact,

\footnotetext{
${ }^{1} \mathrm{JV}$ was a dominant model in 1990s. Merger \& Acquisition (M\&A) was not encouraged until 2003. In 2004, M\&A became a "primary mode" of foreign entry with the majority of FDI carried out in this form. However, in restricted industries, such as automotive, IJV is still a primary entry strategy.
} 
this has been the only mode available, since the Chinese government does not allow wholly foreign-owned enterprises and requires that Chinese partners should hold at least 50\% equity in $\mathrm{IJVs}^{2}$ (Nam, 2011). Empirical evidence suggests, however, that difficulties commonly arise in managing IJVs involving Chinese partners (e.g. Child and Yan, 2003; Cooper and Johnson, 2000). Management controls have also been identified as one of the factors influencing the performance of IJVs and they have received increasing interest from researchers (e.g. Child and Yan, 2003; Yan and Gray, 2001). Despite this attention, the existing literature mainly focuses on the performance consequences of the management controls adopted, and on factors affecting the development of such controls (e.g. Luo et al., 2001; Chalos and O'Conner, 2005; Chen et al., 2010). While the adoption or otherwise of a control mechanism is usually taken as adequate representation of management controls in control-performance relationship studies, the analysis presented by previous studies fails to consider how such mechanisms have been exerted. This at least partly explains an inconsistency in the study results of the above relationship.

This study offers a systematic study of the three dimensions of management controls and their interrelationships. There are calls for the use of a multi-dimensional perspective, to achieve a better understanding of the characteristics of management control in IJVs. Geringer and Hebert (1989) characterise parent controls over IJVs as comprising three primary dimensions, namely, mechanisms, focus, and extent. Mechanisms refer to the means by which control is exercised. Focus specifies the areas of the IJV's operation in which control is exercised. Extent is the degree to which the parents exert control. While some studies combine two or three dimensions in their examination of the nature of controls (e.g. Yan and Gray, 1994; Groot and Merchant, 2000; Kamminga and Van der Meer-Kooistra, 2007; Yan, 1998; Luo et al., 2001), there has not yet been a systematic examination of the interrelationships between the dimensions.

Another underdeveloped area in the literature is the dynamics of IJV control. Previous research has paid significant attention to the early stage of IJV development and takes the view that management controls are decisively shaped at an IJV's formation stage. Within this perspective, IJV managers are viewed as passive rather than active actors and management controls are seen as static rather than dynamic systems. There is little research on how managers from different parents cooperate and compete within the control process. A few previous studies exploring the dynamics of management controls in IJVs offer no supporting empirical evidence on structural reconfiguration of controls (e.g. Yan and Gray, 1994; Kamminga and Van der Meer-Kooistra, 2007). "Structural reconfiguration" refers to changes made to an IJV governance structure, resulting in significant reallocations of management

\footnotetext{
2 It has been a government policy in the last 30 years in China that the foreign partner's shareholding in automotive IJVs should not exceed $50 \%$. Recently, there is a serious open debate among policy advisers, analysts, and related companies on whether the restriction should be relaxed, but there are still no regulatory changes to date (http://epaper.21cbh.com/html/2012-11/21/content_38202.htm?div=-1).
}

controls between partners and/or between the parents and the venture management (Yan, 1998). The lack of supporting empirical evidence on structural reconfiguration is consistent with the reported high stability and success rates of IJVs (e.g. Newman, 1992; Beamish, 1993). The existing literature, however, does not provide a convincing theoretical rationale for, or empirical evidence on how stability of IJV control is achieved, and how the tension between stability and change in IJVs is managed. Managing the tension between stability and change could be considered more complex in IJVs than in single, stand-alone organisations due to IJVs' intercultural and interorganisational hybrid natures.

Aiming to fill these gaps in existing research, the present study adopts an in-depth case study method and examines both parents' management control practices from three control dimensions in the case company. Focusing on the post-formation stage, the case study offers opportunities to observe how the parents cooperate and compete simultaneously in the control process and how the management controls evolve.

Focusing on the post-formation stage of the case company, which was formed in 2003 between a large Japanese company and a large Chinese state-owned company, we examine the multiple dimensions of the management controls exerted by two parents, including the interrelationship between and dynamics of such controls. Through interviewing executives and managers from both parent companies, conducting site observations, and collecting archive data, a "shared but split" management control style is identified from the case study, which is seen as a complement to the types of management style identified by previous studies (Killing, 1983; Schaan, 1983). Fitting into the dynamic environments which the Sino-Chinese IJV faces, the shared but split control model allows two parents to share control access over the entire range of activities, but each possesses dominant control only over certain specific activities. The model provides a structure within which the balance between stability and change is achieved. The study also offers a first observation of evolutionary changes in management controls. Based on observation of how management controls are exerted and evolve, a theoretical framework depicting the interrelationships among multiple dimensions of management controls and their dynamics is developed. Our findings not only enrich the literature on management controls in IJVs, but also highlight possible ways to enhance the effectiveness of management controls over IJVs.

The remainder of the paper is organised as follows. In Section 2, we review theories and empirical studies of management controls in IJVs, and develop a preliminary conceptual framework. Our research methods are then discussed. Section 4 discusses case findings. On the basis of the case study, an integrated theoretical framework is developed. The final section presents conclusions and suggestions for future research.

\section{Theoretical framework}

Below, we introduce the preliminary conceptual framework derived from the existing literature as a guide to the 
study. The meaning of the constructs and their relationships are discussed.

\subsection{Management controls in IJVs}

Based on resource theory, parental control of an IJV implies that the parent firm can ensure the most effective use of the strategic resources it shares with the IJV (Mjoen and Tallman, 1997). In studies of the control and performance relationship, this has traditionally been modelled by relative degree of ownership. More recent studies suggest that ownership may not be the only means of control (e.g. Yan and Gray, 1994; Mjoen and Tallman, 1997), and a shareholder's equity stake in the IJV may not be able to endorse a comparable influence on IJV-related affairs (Nam, 2011). Building on the work of Ouchi (1977), Geringer and Hebert (1989) define control of IJVs as the process by which one entity influences and controls the behaviour and output of another through a wide range of bureaucratic, cultural and informal mechanisms including power and authority. A multi-dimensional perspective on management controls also exists in previous studies (e.g. Geringer and Hebert, 1989; Yan and Gray, 1994; Groot and Merchant, 2000). For a better fit with the focus of the present study on the development process of IJVs at the post-formation stage, we employ Geringer and Hebert's definition of control with a process perspective and examine three primary dimensions, namely, mechanisms, focus, and extent.

As a way of synthesising current research on management controls, a preliminary conceptual framework is developed (Fig. 1). The characteristics of control in an IJV are shown as being capable of description in three dimensions: (1) control mechanisms (i.e. which mechanisms are adopted); (2) control focus - broad or narrow; and (3) control extent - can be described as tight or loose from the perspective of tightness, or identified as dominant, shared, or independent style from the viewpoint of autonomy. As regards the interrelationship between the three dimensions, the extant literature indicates that control mechanisms can be executed tightly or loosely capturing the characteristics of control mechanism and extent, and that there may be other control styles, e.g. split control integrating the dimensions of control extent and focus. The dynamic aspect of management controls may be observed as structural reconfiguration, or as variation within a control pattern. We focus on the latter in order to explore the balance between stability and change.

\subsubsection{Control mechanisms}

Potentially, there could be an endless list of mechanisms that achieve management control in IJVs. For example, the literature emphasises possession of equity and voting rights, staffing, contracts, delegated decisionmaking responsibilities, parent company communications and manager performance incentives (e.g. Killing, 1983; Chalos and O'Conner, 2004; Kamminga and Van der MeerKooistra, 2007). Merchant (1998) offers an all-inclusive way to classify control mechanisms according to the object of control; that is, whether control is exercised over actions, results, or personnel/culture.
Within Merchant's framework, partners can choose action controls in order to ensure that specified desirable actions are taken and undesirable actions not taken. Through fieldwork studying three European alliances, Groot and Merchant (2000) identified "action controls" as the use of joint venture agreement, a board of directors and personnel appointments. Yan and Gray (1994) studied four US-China joint ventures and found two types of action control: board membership and nomination of key personnel. In their examination of the use of control mechanisms in US-Chinese JVs, Chalos and O'Conner (2004), by means of field visits and a questionnaire survey, identified two action controls, namely expatriate staffing and delegated decision-making responsibility. By choosing personnel/culture controls as an alternative or additional mechanism, partners can take steps to ensure that their IJV personnel are willing and able to perform well, and that the IJV culture encourages them to perform well. The personnel/culture controls examined in the studies cited above include socialisation practices and similarity of management systems. Partners can also focus on results. They can monitor results and motivate IJV employees towards desirable results, for example through manager performance incentives and the monitoring of financial performance.

The available research on control mechanisms mainly focuses on whether a mechanism has been employed to analyse the control and performance relationship. There is little research on how the control mechanisms have been executed in practice. The present study follows Merchant's framework and examines whether and how those control mechanisms have been used by the local and foreign partners in the case company.

\subsubsection{Control focus}

Control focus refers to the scope of activities over which parents exercise control. The control focus might be regarded as broad when parents exert control over the full range of activities undertaken by an IJV, or as narrow when parents limit control to specific activities or processes perceived as crucial to attaining strategic objectives. Empirically, Schaan (1983) examined the control focus of ten IJVs in Mexico and demonstrated that firms intend to seek control over specific strategically important activities rather than over the whole IJV. Similar to Schaan, Geringer's (1986) study of ninety developed country JVs also support the existence of parents' choices over broad or narrow control. Their findings raise the prospect of a split control style, one in which a parent firm may exercise dominant control over only a few areas of the venture operation.

Within the context of international JVs, previous studies suggest that narrow control over critical areas is likely to be relevant to both foreign and local parents, while broad control is likely to be important only to foreign partners (e.g. Park, 1996; Tallman and Shenkar, 1994). For example, Luo et al. (2001) provide empirical evidence as to the positive impact of broad control on foreign parents' level of satisfaction, but not on Chinese parents' satisfaction. They argue that Chinese firms focus on the objective of acquiring foreign technologies and have little concern as to the overall outcome of IJV operations. We question whether the 


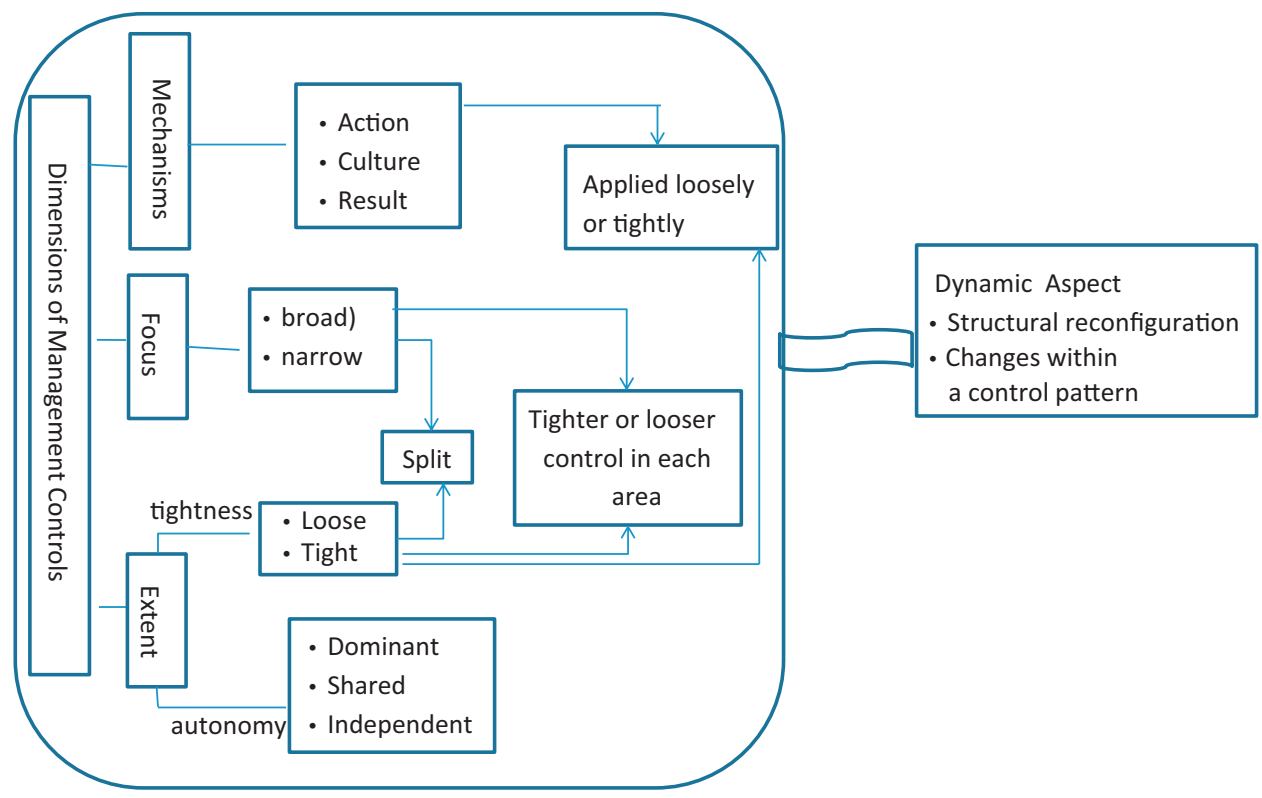

Fig. 1. Preliminary theoretical framework.

objectives and control focus of Chinese firms have remained unchanged since this study was conducted.

\subsubsection{Extent of control}

The extent of control refers to the degree to which a parent exerts control over the IJV (Yan, 1998). Assessing a partner's extent of control is problematic. Different perspectives may also be adopted.

Extent of control is initially conceptualised as the degree to which the decision-making process is centralised. Killing (1983), for example, studied control extent in thirtyseven JVs from developed countries by examining parents' influence on nine types of decision: pricing policy, product design, production scheduling, manufacturing process, quality control, replacement of managers, sales targets, cost budgeting and capital expenditures. He identified three types of controls: dominant, shared and independent. By adopting a dominant control model, the dominant parent manages the JV as if it was a wholly owned subsidiary, while the other parent plays a passive role; the board of directors, although containing executives from each parent, plays a largely ceremonial role. In a shared control venture, both parents play a meaningful managerial role and usually send managers to form a board that has real influence. In an independent venture, the general manager is free to make decisions alone.

Earlier studies advanced the proposition that dominant control of IJVs by one parent will contribute to superior performance, in that it will bring IJVs closer to a unitary firm and be easier to manage (Killing, 1983), and offers an ability to determine the most effective use of strategic resources (Mjoen and Tallman, 1997). However, a policy of dominant control might also negatively affect the relationships between partners. Some studies have found, for example, that there tends to be a positive association between satisfactory performance and shared control between the foreign and local partners when IJVs are formed between developed and less-developed country partners (e.g. Beamish, 1988, 1993; Child and Yan, 2003; Yan and Gray, 1994).

The above decision making perspective on the extent of control is criticised as presenting a very limited view of control extent by focusing on the autonomy of IJVs' personnel. It also implicitly suggests that parents only pursue broad control over the overall IJV, rather than targeting specific activities. To address the limitations of the decision making perspective, Groot and Merchant (2000) describe the extent of control as control tightness: controls can be regarded as tight (loose) when they provide a partner with high (low) degrees of certainty that personnel in its IJV will act as the given partner wishes. They further argue that tight control can be exerted through any mechanism and each control system can be used to exert tighter or looser control. While the decision making perspective focuses on control access to all important areas through IJVs' personnel, Groot and Merchant's control tightness perspective provides a framework for examining the tightness of each control mechanism and of control over each individual area of an IJV's operation. Their empirical work investigates the tightness of control mechanisms, but not of control areas.

In focusing on the relative extent of a parent's control over the IJV, neither of these perspectives individually can fully capture the concept. Most researchers measure this subjectively, by investigating perceived overall control from the viewpoint of managers (e.g. Child and Yan, 2003; Yan and Gray, 1994). The present study considers these two perspectives through examining the control tightness of each mechanism employed and of control on all important decisions to assess the relative extent of control exerted by a parent. 


\subsection{Interrelationships among three dimensions}

Control of IJVs was initially studied in relation to one of the three different dimensions outlined above. Since the late 1980s, however, there have been calls for an integrative approach, in which the three dimensions are brought together in order to obtain a more thorough understanding of the control phenomenon in IJVs (Geringer and Hebert, 1989; Yan and Gray, 1994). Some recent studies have considered two or three dimensions in their description of the characteristics of controls (e.g. Yan and Gray, 1994; Groot and Merchant, 2000; Kamminga and Van der MeerKooistra, 2007); however, those dimensions are usually treated independently. Among these studies, only Groot and Merchant (2000) explicitly discuss the relationship between control mechanisms and the extent of control. They argue that parents can exert each control mechanism tightly or loosely, which captures the characteristics of control mechanisms and extent. Some researchers implicitly integrate the dimensions of control focus and extent, and argue that a parent may exercise dominant control over only a limited range of activities undertaken by an IJV, which raises the prospect of a split control style (Schaan, 1983; Geringer and Hebert, 1989). This split control style captures the characteristics of a tight control with a narrow focus. However, no direct attempt has been made to develop a systematic approach to examine the relationships between the dimensions of control. The lack of work in this area raises questions as to the validity of existing control-performance studies. For example, while a control mechanism could be applied tightly or loosely, as suggested by Groot and Merchant (2000), the adoption of a particular mechanism to represent a partner's control would clearly in itself not capture the full impact of control on performance. The assessment of overall extent of a partner's control, and therefore the impact of control on performance, requires a better understanding of the nature of control. A systematic study of not just the multiple dimensions of control, but also the interrelationships of the dimensions could be a step forward in this direction.

\subsection{Dynamics of management controls on IJVs}

Do management controls in an IJV change over time? According to Stinchcombe (1965) and Scott (1987), organisations are likely to retain many of the features acquired at the time of their birth, a phenomenon which is referred to as "organisational imprinting." A small number of studies within the context of IJV's control have provided empirical evidence as to organisational imprinting. Yan and Gray (1994) observed changes in the bargaining power of partners but no significant structural reconfiguration in the JVs they studied; their research thus supports the existence of organisational imprinting. Gray and Yan (1997) compared Chinese-US JVs established before 1990 with those formed in the 1990s, and found that equity distribution and management control structures in JVs established before 1990 were likely to be retained, despite changes in the parents' relative bargaining power over time. On the other hand, Bjorkman and Lu (2001) observed changes in human resource management (HRM) practices in their study of
Chinese-Western JVs. The Chinese General Manager in one of their case companies was eager to introduce new HRM policies from the foreign parent company, despite the fact that initially the IJV had adopted certain HRM policies similar to those in the Chinese parent company. Kamminga and Van der Meer-Kooistra's (2007) case study shows how institutional factors, especially governmental regulations, do not prompt shifts in the patterns of management controls, but they call for further study on possible changes within a pattern of controls.

Despite empirical evidence supporting the existence of organisational imprinting, no further study sheds light on how stability has been or could be maintained in the process of development of IJVs, and how the tension between stability and change in IJVs has been managed, while it is widely accepted that IJVs represent an inherently unstable organisational form.

\section{Research methods}

\subsection{Case selection}

Parkhe (1993) has argued that the convergence of "hard" methodological approaches with "soft" behavioural variables may hinder theory development in the study of IJVs. He suggests redirecting the focus of IJV research using case studies in order to obtain a deeper understanding of interfirm cooperation. Some researchers have applied such a case study method in their works (e.g. Yan and Gray, 1994; Groot and Merchant, 2000). In this study, a Sino-Japanese joint venture is studied and a detailed case description is provided in the next section. The use of a single case strategy is justified by the longitudinal nature of in-depth study on the dynamic characteristics of management controls (Yin, 2009; Dekker, 2004).

Three main factors were taken into account in selecting the case. First, the study was limited to IJVs in the automotive industry in China. Because of its scale and impact on a country's economy, the automotive manufacturing industry is a vital element in the economy of many industrialised countries, including the United States, Germany, Japan, and South Korea, as well as a number of emerging economies, including China. The rapid expansion of the Chinese vehicle market $^{3}$ has attracted multinational automotive companies and the model of an IJV is a common global business model adopted in the industry. However, because of the significance of this particular industry to the economy, the Chinese government maintains control over domestic companies to a certain extent, with further effects on IJVs in this sector. Changes in the institutional environment and market may undermine the continuing validity of findings from previous studies in developed countries, as well as earlier studies in China. The impact of such changes warrants further study of the kind we present in this paper. Second, the case company needs to have been in operation for a period of time and the structure of management controls must have remained stable, so that data on the dynamics

\footnotetext{
3 Based on the sales of new cars in 2009, China has become the largest car market, overtaking the United States.
} 
of management controls within a control pattern are available. The case company appeared appropriate here, having already been in existence for six years with no significant changes in management control structure at the time of the study. The final, practical factor concerns access to both parent companies and to the joint venture itself. This proved very difficult, not just because of the unavailability of interviewees but also because the topic was perceived by many of those concerned to be too sensitive. Despite such difficulties, we nevertheless obtained support and assistance from personal and professional contacts, who provided us with necessary access to the case company.

Conducting in-depth case study in IJVs proved very difficult. Apart from the general sensitivity of case study research on IJVs control (Yan and Gray, 1994; Groot and Merchant, 2000), there is a lack of trust among Chinese managers of foreign academic activity, as well as a specific lack of trust felt by foreign parents of Chinese academic activities in our case. ${ }^{4}$ As far as securing access to informants and ensuring open discussion in interviews are concerned, the privilege of being funded by a Chinese and a UK grant allowed us to follow a number of procedures calculated to minimise difficulties. When contacting Chinese executives and managers, we stressed that our study was a Chinese government funded project led by a Chinese professor; when in contact with the Japanese side, we emphasised instead that our study was a CIMAfunded project led by a UK-based researcher. This strategy facilitated our data collection and helped increasing the reliability and richness of data. ${ }^{5}$

\subsection{Data collection}

The data presented in this study were collected from interviews, direct observations and archives during the years 2008-2010.

In the course of research, we conducted in-depth interviews with executives of both the Chinese and Japanese parents, and with managers of the joint venture expatriated from the two parents (see Appendix A for further details of informants). The semi-structured questionnaire that guided the interviews is also given in Appendix A. Interviews were conducted by means of face-to-face meetings, with each interview lasting an average of $2 \mathrm{~h}$ (except one that was conducted in written form). The face-to-face interviews were tape-recorded, transcribed and analysed immediately.

Two site visits were made to the IJV and one to the headquarters of the Japanese parent in order to observe

\footnotetext{
4 Regarding the factors that foster lack of trust by Chinese managers in foreign academic activities, see footnote 7 in Chalos and O'Conner, 2004. On lack of trust of foreign partners in Chinese academic activities, an informal discussion between our Japanese researcher and the Japanese informants before the study suggests that foreign parents worry that any information disclosed to Chinese academics may be communicated to the Chinese government and Chinese partners, especially if their Chinese partner is a SOE.

5 We have considered ethical issues as regards to this strategy and taken two steps to ensure it is still acceptable. First, we ensured the information we gave remained true while emphasising different features of the study Second, we treated the information from the interviews as confidential.
}

the operation of the production system at both sites. In addition, archival data were collected, including statistics of the performance of the joint venture, the joint venture's and the parents' organisational charts, corporate brochures, published case descriptions, newspapers, magazine reports, and books.

\subsection{Data analysis process}

Since the case study focuses on how controls have been executed and evolved in operational processes, we investigated decision-making and day-to-day operational control in order to identify the particular control mechanisms adopted and the characteristics of controls from a dual-parent perspective.

The data analysis followed an iterative process of moving back and forth between the preliminary and developed theoretical frameworks, and our recorded field data. A qualitative software package (Nvivo8.0) was used to facilitate coding and to ensure that there was no selective choice of data in developing the study's findings. At least two of the four authors participated in the data analysis. The interpretation of the data is discussed and confirmed by the four authors. Use of multiple sources of evidence allows data triangulation during the data analysis process. For example, interview data were compared between the points-of-view of Chinese and Japanese managers, as well as, and alternatively, from archive data. Ambiguous or vague points were clarified by further fieldwork. The process of analysis fell into three stages described below.

In stage 1 , we coded all data into two categories for each parent, namely, control mechanisms and decisionmaking areas with control access. These two categories were chosen because they fully captured the characteristics of management controls in terms of three dimensions according to the preliminary theoretical framework. The classification of control mechanisms followed the definitions given by Groot and Merchant's (2000) framework and considered the common control mechanisms identified in previous studies as discussed in the earlier section on the theoretical framework. Consistent with previous studies (e.g. Killing, 1983), nine decision-making areas were included for the second category. A case description was developed at this stage as a summary of the characteristics of control mechanisms and control access for each parent. The case description and the transcripts of the interviews have been sent to the respective interviewees for approval, and no objections were received from the interviewees.

In stage 2, the field data were further analysed and coded into three categories for each parent: the control tightness of each control mechanism, the control tightness in each decision-making area, and how they have changed. The data coding based on the preliminary theoretical framework was completed at the end of this stage. As a result, control mechanisms adopted by both parents were identified, the control extent and focus were assessed, the interrelationship between dimensions of controls was established, and any changes were observed.

In stage 3, a revised theoretical framework was developed based on the data analysis, and the field data were 
re-coded according to the developed theoretical framework.

\section{Case analysis and discussion}

Guided by our preliminary theoretical framework, this section presents observations and analysis of the characteristics of three control dimensions, their interrelationships and dynamics, after a brief introduction to the establishment of the case company. The characteristics of management controls exerted by two partners and their changes are summarised in Fig. 2. In addition to the mechanisms employed and the observed control focus and extent, Fig. 2 also shows the changes in the tightness of controls over particular activities. The table's last column indicates the two parents' relative extent of control and their dynamics. At the end of the analysis, an integrative theoretical framework is then developed to depict the interrelationships among the three dimensions of controls and their dynamics, as shown in Fig. 3.

\subsection{Establishment of the case company}

As a large-scale joint venture company, the case company YQJT was set up in 2003 by a Chinese motor company, "YQ Group Corporation", and a Japanese company, "JT Motor Corporation". 6 The Chinese and Japanese partners each have a $50 \%$ total shareholding. As a state-owned firm, YQ Group Corporation (hereafter YQ) is one of the largest Chinese automotive companies and was formed in the 1950s. The company has two brands that have been regarded as a symbol of pride for the country from the 1950s to the present day. JT Motor Corporation (hereafter JT) is a multinational corporation with headquarters in Japan. It is one of the world's largest automakers, with factories in most parts of the world manufacturing or assembling vehicles for local markets. JT has long been regarded as an industry leader; its operation and management systems are described as "the JT way". The profile of YQJT and the two parents is provided in Appendix B.

Despite its prominence and reputation, JT is regarded as a "latecomer" in the Chinese automotive market. While other leading multinational enterprises engaged in joint ventures with Chinese companies in order to produce passenger cars in the 1980s, JT established its first passenger-car joint venture, TSJT, with one of the "Small 3"7 Chinese companies in 2000. Choosing a weaker partner reflects JT's desire to retain dominant control over the joint venture. However, soon JT realised that its business would not grow as fast as expected if it worked with a small company, for two reasons: (1) its Chinese partner only had a licence to produce small-engine cars (1.6 L or below); (2) the Chinese automotive industry is under strict control of Government and the Chinese government has preferential

\footnotetext{
6 The names of the case company and its parents are disguised to ensure confidentiality.

7 Based on capacity of production, the three largest Chinese automotive companies are regarded as the "Big 3," YQ being one of them. The three smallest companies are regarded as the "Small 3."
}

policies for large companies; so working with a small company put JT at a disadvantageous position. Establishing an IJV with YQ meets JT's best interests. By that time, however, JT had already established two joint ventures in China and was not able to engage with an additional Chinese company because the Chinese government sets a restriction at two on the number of IJVs for each foreign company in the automotive industry.

Meanwhile, YQ had an intention to engage in a strategic partnership with JT for the following reasons: (1) the company had been ambitious of developing its own brand and product, and learning through JVs is a strategic choice. (2) The company had started to learn about JT's production and management system from the 1970s onwards, but had not been particularly successful; an IJV with JT could make a difference to the learning experience. (3) The company had only one IJV and wanted to reduce its dependence on its foreign partner by engaging with another one.

Mutual interests accordingly motivated both YQ and JT to construct their strategic partnership. Later, YQ merged with the "small" Chinese parent company of TSJT and thereby formed YQJT with JT. YQJT has enjoyed considerable success from 2003 to the time of study. Its annual production has increased from 50,000 to 420,000 cars in 2010; annual revenue and profit have increased about 6 times. Both parents set target market share as reaching $10 \%$ in 2010. Although affected by the economic recession, the company's market share in China achieved 6.5\% and ranked as number 4 in the industry in 2008 .

\subsection{Control mechanisms employed by both parents}

The investigation revealed the control mechanisms employed by both parents as shown in Fig. 2. JT mainly employs action controls including board of directors and personnel appointment, and such culture controls as adopting similar production and management systems, and mentoring and training. In addition to the same action control mechanisms as employed by JT, YQ also relies on result controls. Such result controls include manager performance incentives and budgeting.

\subsubsection{Board of directors and personnel appointment $-Y Q$ and $J T$}

YQJT is managed by its board of directors (BoD) and the Operation and Management Committee (OMC). There are 10 directors on the BoD, including 6 executives and 4 nonexecutives. Daily activities are managed by the OMC, which consists of 4 executive directors. OMC meets every two weeks, having the union leader and chief finance manager sit in.

Executive and managerial positions, from directors to functional managers, are held equally, in terms of numbers, by expatriates from YQ and JT. JT sends 70 staff to YQJT to cover these positions. YQ holds the same seats as JT does. The manager and deputy manager in a department shared by YQ and JT have equal authority. All decisions are made by consensus, and neither partner can be outvoted. This arrangement includes significant decisions that have to be made by the BoD, as well as operational decisions made by the OMC or in the factories and functional departments. "All 
P. Li et al. / Management Accounting Research $x x x$ (2013) $x x x-x x x$

\begin{tabular}{|c|c|c|c|c|c|}
\hline & \multicolumn{2}{|c|}{ Mechanisms } & \multirow[t]{2}{*}{ Control Focus } & \multirow{2}{*}{$\begin{array}{l}\text { Extent of control } \\
\text { over a particular activity }\end{array}$} & \multirow{2}{*}{$\begin{array}{l}\text { A partner's Relative } \\
\text { Extent of Control and } \\
\text { the dynamics }\end{array}$} \\
\hline & Choices & $\begin{array}{l}\text { Extent of } \\
\text { control }\end{array}$ & & & \\
\hline \multirow[t]{2}{*}{ YQ } & $\begin{array}{l}\text { Action controls: } \\
\text { - BoD } \\
\text { - Personnel appointment }\end{array}$ & tight & \multirow{2}{*}{$\begin{array}{l}\text { Broad: } \\
\text { focus on the } \\
\text { entire range } \\
\text { of activities }\end{array}$} & $\begin{array}{l}\text { Tighter on } \\
\text { - Employees' hiring, firing and } \\
\text { appraisal/punishment (+++) }\end{array}$ & \multirow{2}{*}{$\begin{array}{c}\text { looser } \\
1- \\
15 \\
1 \\
\vdots \\
\vdots \\
\text { equal }\end{array}$} \\
\hline & $\begin{array}{l}\text { Result controls: } \\
\text { - Managers performance } \\
\text { incentives } \\
\text { - Budgeting }\end{array}$ & tight & & \multirow{3}{*}{$\begin{array}{l}\text { Equal on } \\
\text { - Budgeting } \\
\text { - Employees' salaries and benefits } \\
(+++) \\
\text { Tighter on } \\
\text { - Introducing new products (---) } \\
\text { - Manufacturing planning, } \\
\text { - Pricing } \\
\text { - Procurement } \\
\text { - Cost management } \\
\text { - Quality control }\end{array}$} & \\
\hline \multirow[t]{4}{*}{ JT } & $\begin{array}{l}\text { Action controls: } \\
\text { - BoD } \\
\text { - Personnel appointment }\end{array}$ & tight & \multirow{4}{*}{$\begin{array}{l}\text { Broad: } \\
\text { focus on the } \\
\text { entire range } \\
\text { of activities }\end{array}$} & & \multirow{4}{*}{ 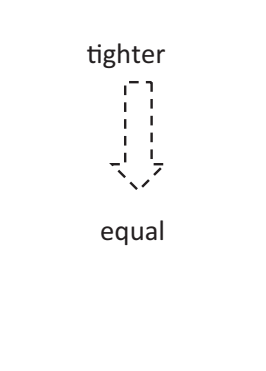 } \\
\hline & $\begin{array}{l}\text { Personnel/culture } \\
\text { controls } \\
\text { - Similar production and }\end{array}$ & tight & & & \\
\hline & - Mentoring and training & & & \multirow{2}{*}{$\begin{array}{l}\text { Equal on } \\
\text { - Budgeting } \\
\text { - Employees' salaries and } \\
\text { benefits(---) }\end{array}$} & \\
\hline & $\begin{array}{l}\text { Result controls: } \\
\text { - Budgeting }\end{array}$ & Loose & & & \\
\hline
\end{tabular}

- $(+++)$ : the extent of control becomes tighter

- (--): the extent of control becomes looser

- $\overrightarrow{-}-\vec{\imath}$ : the change of the extent of control

Fig. 2. The case analysis.

documents have to be double signed by the Japanese and Chinese managers - no exceptions - so we are in meetings all the time," confirmed both the Chinese and Japanese financial managers.

\subsubsection{Manager performance incentives $-Y Q$}

Although the recorded salaries of expatriate staff from both parents are linked to YQJT's annual profit and the policy for doing this was set in the joint venture agreement, it is not necessarily identical to the salaries paid by the parent companies to staff. Only the Chinese managers' actual remuneration is directly linked to achievement of budgeted profit. JT's expatriate staff's remuneration package is designed on the basis of JT's policy and not directly affected by the financial performance of YQJT. This shows that manager performance incentives as a culture control mechanism are only employed by YQ.

\subsubsection{Adopting similar production and management systems - JT}

YQJT adheres to JT's production and management system. The following quotations illustrate the similarity between these systems:

The manufacturing and management systems are a direct copy of our model. The operational procedure is accepting order[s] then planning manufacturing, because we believe in "customer is the first priority"; we train the frontline workers, because we know how to make a top quality car (Japanese Financial Manager).

Consistent with this comment, the Chinese managers we interviewed also rank the production management system as one of the most important contributions from the Japanese side.

\subsubsection{Mentoring and training - JT}

To make JT's model work efficiently in YQJT, in addition to the large number of expatriate staff, JT still sends short-term and project-based mentoring teams to YQJT at the beginning of a new project. The size of the team varies, from a few to hundreds of people, and the mentoring teams stay for a period ranging from months to years, depending on the nature of the project. "They are like our teachers. They leave when our front workers are able to do the job independently," the Chinese informant said. In addition, YQJT sends hundreds of frontline workers every year to JT factories in Japan for training. New Chinese graduates are preferred in recruiting because they seem easier to fit into the JT production and management model.

\subsubsection{Budgeting and conflict resolution - YQ and JT}

Although the approval of any budgetary items comes from the consensus between both parents, budgeting is mainly the concern of the Chinese parent, from the perspective of the format, procedure, and process control.

YQJT receives a requirement to produce budgets for the subsequent year from YQ in September. The format and contents are set out by the Chinese State-Owned Assets Supervision and Administration Commission of the State Council(SASAC). The budgets include "master budgets" and "functional budgets." The focus of master budgets is the target profit and sales negotiated by the partners. Based on forecast figures provided by YQJT, the directors negotiate and agree on targets according to the objectives of their 
parent companies. The functional budgets focus on cost control, and are in essence a set of budgets of controllable costs and expenses for each department.

In the process of implementation, YQJT conducts a mid-year performance and environment analysis and then proposes a profit target adjustment to the parents. Usually the proposal is questioned and challenged by YQ, but barely by JT. YQ further requires a monthly balance sheet, profit and loss account, cash flow statement, product profitability analysis, and quarterly budgeting variance analysis. As part of the last of these, YQ requires the analysis of whether annual targets can be achieved, based on what has been achieved so far and on the updated forecast for the rest of the budgeting period. In contrast to YQ JT requires only a brief performance report monthly from YQJT, and does not request budgeting variance analysis. Japanese managers also say that the reporting system between JT and YQJT is mainly informal. "We keep informal and frequent contact with the headquarters and do not need much formal budgetary control," commented the Japanese Financial Manager. This view is reinforced from another perspective by the Chinese financial manager: "The structure of products has been determined at the product design stage, and the prices of all parts are mainly under the control of JT. They do not need many reports during the manufacturing process."

Two areas of conflict commonly arise during the budgeting process: (1) conflicts between parents' objectives and (2) gaps between the parents' expectations and the YQJT forecast. The second of these areas of conflict resembles the situation in a unitary company, where it would be resolved by the efforts of managers on cost reduction and efforts on the part of the BoD as regards adjusting marketing strategy or making a compromise on targets. The first area of conflicts, which focuses mainly on the setting of a profit target, arises from a disparity as regards the parents' objectives and the differing degrees of control they exercise over the profitability of YQJT.

JT and YQ both pursue profit and growth but prioritise these differently: JT's primary objective is market share in the Chinese market, while YQ does not want to sacrifice profit for growth. "JT focuses on market share. We want to ensure customer's satisfaction," observes a Japanese informant. This view is confirmed by a Chinese counterpart: " JT focuses on market share and would like to increase it even if it is at the cost of profit. But we do not want to sacrifice profit." YQ's stronger desire for profit is also reflected in comments made by the Japanese Financial Manager: "YQ is a state-owned company. The Chinese Government sets profit target for YQJT, which is very challenging from the viewpoint of all Japanese managers, and we have to try very hard to work out the ways to achieve it."

For our study, the principal causes of the gap between the extents of each company's desire for profitability can be identified as follows:

First, for JT, because the establishment of YQJT is part of its development strategy in China, market share is more important than profit. The managing director of JT we interviewed stated the objective of YQJT as "getting involved more deeply in Chinese society and expanding the enterprise into the biggest market, not just the car market, but also the property market, environmental technology market ...". A well-known JV fits well into JT's vision in China.

Second, for YQ pursuing profit is a fall-back position after it fails to achieve the primary objective. As a large SOE, obtaining technology has been YQ's (indeed the whole Chinese automotive industry's) primary objective for its IJVs. For the Chinese government, the initial and most important target of setting up IJVs in the automotive industry was as a means of obtaining technology and speeding up the development of the industry - a strategy known as the "exchange-market-for-technology." This has been YQ's primary objective because of YQ's significant position in the industry. Evidence of the implementation of such strategy in practice can be found in the comment made by the Japanese managing director we interviewed, who has worked in China since the 1980s: "To learn from IJVs and enhance their own competitive advantages, it has been the vision shared by the Chinese government and their SOEs. I respect it, but it takes time for an industry to develop."

Until now, however, it has been commonly accepted by the government, industry analysts and the wider society in China that the automotive industry has failed to achieve this primary objective. ${ }^{8} 70 \%$ of cars sold in the Chinese market are produced by IJVs, which use foreign parents' brands; there are still no Chinese national brands which are able to compete with those from America, Japan and Europe. Nam (2011) also concludes that IJV arrangement does not serve well the exchange-market-for-technology strategy in his study of two Sino-foreign automotive IJVs. Under these circumstances, profit is seen as the second best objective for IJVs in their mission to help develop the Chinese automotive industry. "We could not accept financial loss from our IJV. We must make money to support the development of our own brand in our parent company." This was the view of the Chinese financial manager.

Third, the profit pool available to JT may be larger than the IJV itself, while distributed profit is the main financial income from this IJV on the YQ side. By comparison, JT benefits financially from YQJT in many other ways because of their contribution of technology and supplier networks. These additional sources include equipment sales, technology transfer fees, related transactions with suppliers, and other inter-organisational transactions. The Chinese managers once analysed and identified 18-20 sources from which JT could benefit from YQJT, in addition to distributed profit.

This situation makes the profitability of YQJT more important to YQ than to JT. Furthermore, profitability is significantly affected by the negotiation of transfer prices and

\footnotetext{
8 For example, China's National Development and Reform Commission issued a report in 2008 and warned that "the extent that the Chinese automobile industry relies on international ventures has exceeded the extent of this in any other countries."

"In 30 years time, Chinese automobile industry experienced rapid growth; however, the failure of 'exchange - market - for - technology' is an unarguable reality. We have not seen the success as it happed in Japan or Korea. The Chinese car market was kidded as an 'expo of international cars,"'commented by a famous Chinese industry journalist Mr. Chen Gang Rui in a TV live interview on 21/05/2011 with Mr. Rupert Stadler, the Chairman of Audi (http://jingji.cntv. cn/programe/hqcjlx/index.shtml).
} 
decisions on the product portfolio and pricing by the parent companies, rather than being determined solely by market performance. Although the principles for transfer pricing were negotiated in the formation stage of YQJT and stated in the JV agreement, the specific figures for each year vary depending on the items that are transferred. For instance, the technique transferring fee is identified by the Chinese executive we interviewed as one of the most important factors affecting cooperation between the two partners. Chinese managers blame JT managers for not communicating information to them on time, and admit that they do not completely trust the information provided. "We do not know exactly how much a transferred part should be, and we do not trust the price offered by JT either. So we usually cut $20 \%$ of the initial price provided by JT as the starting point of the negotiation." On the other hand, decisions made as regards new product introduction and pricing remain primarily under the control of JT because of their superior position in technology and products information. This further increases the extent of JT's control over the profitability of YQJT.

Circumstances of this kind make negotiation a part of daily life in YQJT: there is less of a profitability-focus due to larger number of benefiting sources but stronger control over YQJT profitability held by JT, and stronger desire for profit but a weaker position in profit control on the part of YQ. Negotiation occurs at executive and also managerial levels, depending on the significance of the item. "We are in meetings most of the time," reported all the managers we interviewed. Furthermore, managers ranked improved negotiating ability as their most important work-based learning outcome. An important job for the Chinese managers is the use of budgetary control to monitor every step of the operation process in order to ensure the achievement of the profit promised by JT through approval of the annual budget. The observation of negotiation during the operational process at both executive and managerial levels provides empirical evidence that both collaborative and competitive forces are simultaneously at work within IJVs (Chalos and O'Conner, 2004).

In summary, as shown in Fig. 2, the Chinese parent YQ has employed action controls, including board of directors and personnel appointment, and result controls as manager performance incentives and budgeting. Japanese parent JT has employed the same action controls, together with such personnel/culture controls as adopting similar production and management system, and mentoring and training. They still participate in budgeting control, but mainly take a passive role. Observation of how control has been exerted shows that the bargaining process extends from the formation to the operation of the JV, while most previous studies that apply bargaining power theory only focus on the formation stage. This brings the elements of support and challenge from two parents into the relationship between the managers, and the extent of information asymmetry affects the cooperation between the managers.

\subsection{Control focus}

The analysis of what and how the control mechanisms have been executed reveals that both partners have gained control access to the entire range of activities and have exercised overall control; therefore, their control focus can be regarded as broad.

For JT, it is achieved mainly by action controls (such as BoD, personnel appointment) and culture controls (including adopting similar production and management systems, and mentoring and training). By means of retaining a large number of expatriates covering all important positions, managing the production activities in "JT's Way," and mentoring and training frontline workers, the information asymmetry arising from physical and environmental distance is reduced and JT is given confidence in protecting its intangible assets and implementing its strategy in all important areas. For YQ the action control mechanisms provide control access into all important decision-making areas; however, budgeting control is still important in providing broader control access into operational activities and processes due to their inferior position in the control of product design and manufacturing.

While the broad control focus on the part of JT matches Japanese organisation culture and is consistent with previous studies (e.g. Calantone and Zhao, 2000; Kopp, 1994), such a focus from the Chinese partner is not. Chinese partners, as described in such studies (e.g. Luo et al., 2001), focused their control on specific areas and had no motivation for broad control. In our case company, on the other hand, the Chinese partner has shown a strong desire for broad control and has actually obtained control access to all activities. Two factors contributing to this change can be identified from the case study: (1) the scope of learning has changed. While most Chinese companies during the earlier phase of Chinese market economy development focused on learning of manufacturing technologies, YQ intends to learn the management and production system, which covers a broader range of activities. (2) While learning is still an important objective, YQ has a strong desire for profitability on the part of its IJVs. Since profitability is affected by the entire range of activities undertaken by a company, this learning goal motivates YQ to pursue overall control. The change which has taken place might accordingly reflect the reform of Chinese SOEs, which are transforming themselves into more independent economic entities and focusing more on financial outcomes.

\subsection{Control extent}

In Fig. 1, we assessed a parent's relative extent of control from two perspectives: the extent of control on each important decision-making area based on an autonomy perspective and of control mechanisms based on a control tightness perspective.

Since both partners have equal control access to the entire range of activities, it is a shared control style from the perspective of autonomy. However, this does not mean an equal influence from the two partners on decision-making across all activities. Referring to Killing (1983) and Child and Yan (2003)'s frameworks, we asked interviewees to assess their relative impact across the following decision areas: (1) introducing new products, (2) manufacturing planning, (3) pricing, (4) procurement, (5) cost management, (6) quality control, (7) budgeting, (8) employees' 
hiring, firing and appraisal/punishment, and (9) employees' salaries and benefits. We found consistent acknowledgement that JT exerts more influence in areas (1), (2), (3), (4), (5), and (6); YQ has more influence in area (8); and both companies have equal influence in areas (7) and (9). The Chinese financial manger gave the following examples: "in the areas of production management, the managers from JT play the major role because they understand the technology and products better; in HR management, Chinese managers' opinions are taken more seriously now because we understand the regulations and culture better." Overall JT possesses tighter control over more activities as compared with YQ. as depicted in column "Extent of control over a particular activity" of Fig. 2.

Applying Groot and Merchant's (2000) tight or loose perspective, the mechanisms adopted by both parents can be regarded as "tight", except for budgetary control for JT, which might be regarded as "loose", as shown in Fig. 2. This assessment is based on the positive comments made by executives and managers as regards achievement of both parents' objectives, and the observed strong desire and high level of effort directed towards protecting their parents' interests, as presented in the analysis and discussion of the control mechanisms. For the purpose of control, JT does not rely on budgeting because of their superior knowledge position in products and production and management systems. JT's equal influence in decision-making area of budgeting is mainly achieved by action control mechanism, not budgetary control. For YQ, budgetary control is an important supplementary to the action controls to reduce information asymmetry and ensure the achievement of YQ's strategic objectives. This mechanism is particularly important to YQ because of the existence of conflicts of objectives and of the gap as regards the extent of control over profitability between the two partners.

Rather than assessing a parent's relative extent of control subjectively from a manger's viewpoint, (Yan and Gray, 1994), we argue that it is better assessed on the basis of the control extent of its chosen mechanisms and its control over specific activities. In the case company, both parents applied their control mechanisms tightly, except for budgetary control (which was loose from the JT side). However, JT exercises tighter control on more activities. As a result, the relative extent of overall control exercised by both partners might be initially regarded as unbalanced: JT has a tighter overall control than YQ does, despite their 50/50 ownership and BoD seats.

It is worth noting that, while there are arguments as to whether equity structure is equivalent to management control, our findings open up a different perspective on this issue. In our case, 50/50 ownership does determine shared management features and offers both parents control access to entire range of activities, but it does not award equal control tightness on all activities or of control mechanisms, which is consistent with Nam (2011) who observed that a shareholder's equity stake in the IJV has failed to endorse a comparable influence on technical aspects of the IJV-related affairs within the context of IJVs in Chinese automotive industry. Consistent with Yan and Gray (1994), our study provides additional evidence that equity structure has an impact on only board membership, not on other control mechanisms or dimensions.

\subsection{Interrelationships}

On the basis of our observations, interrelationships between the three dimensions of control can be synthesised as follows:

First, a parent's management control style overall is determined by the characteristics of control extent and focus. Our case study indicates a special management control style that may be regarded as a shared but split model ${ }^{9}$ : two partners share control over the entire range of activities with broad control focus, but each possesses tighter control over only certain activities, as assessed by the autonomy perspective of control extent. This style differs from Killing's (1983) notion of shared control, which only reflects equal influence by partners on decisions, and also differs from Schaan's (1983) notion of split control, which only recognises dominant control over selective activities.

Second, a control mechanism can be exerted tightly or loosely, cutting across the established dimensions of mechanisms and extent. This supports Groot and Merchant's (2000) argument, for which there is no empirical evidence in their study.

Third, the choice of control mechanisms is affected by the control focus. Both parents in the case company have broad control focuses, hence the mechanisms they have chosen should provide, and indeed have provided, them with access to the entire range of activities. The large number of expatriate staff and the adoption of a similar production and management system for JT, as well as personnel and budgetary control for $\mathrm{YQ}$, offer both parents broad control access.

These findings are synthesised in Fig. 3, with area A representing the part of a control model with structural stability and area B showing the dynamics. We identified the essential features of the control model in the case company as shared control with access to the entire range of activities for both parents and particular mechanisms to achieve such access and control. This has provided further supporting evidence to preliminary theoretical framework (Fig. 1). Interrelationships between the dimensions offer a structure that allows evolutionary changes in management controls, affecting a parent's relative control extent without unsettling the overall control structure. Shared but split control style cuts across areas A and B, which is further discussed below.

\subsection{The dynamic nature of management controls}

The most important result from the study is the recognition of how the control has evolved within the established structure. The study shows that the relative extent of control between two parents has changed through the shifted control extent in some areas, while the corporate governance structure and control mechanisms adopted by both

\footnotetext{
9 For a more detailed description of the shared but split model, see Li et al. (2011).
} 


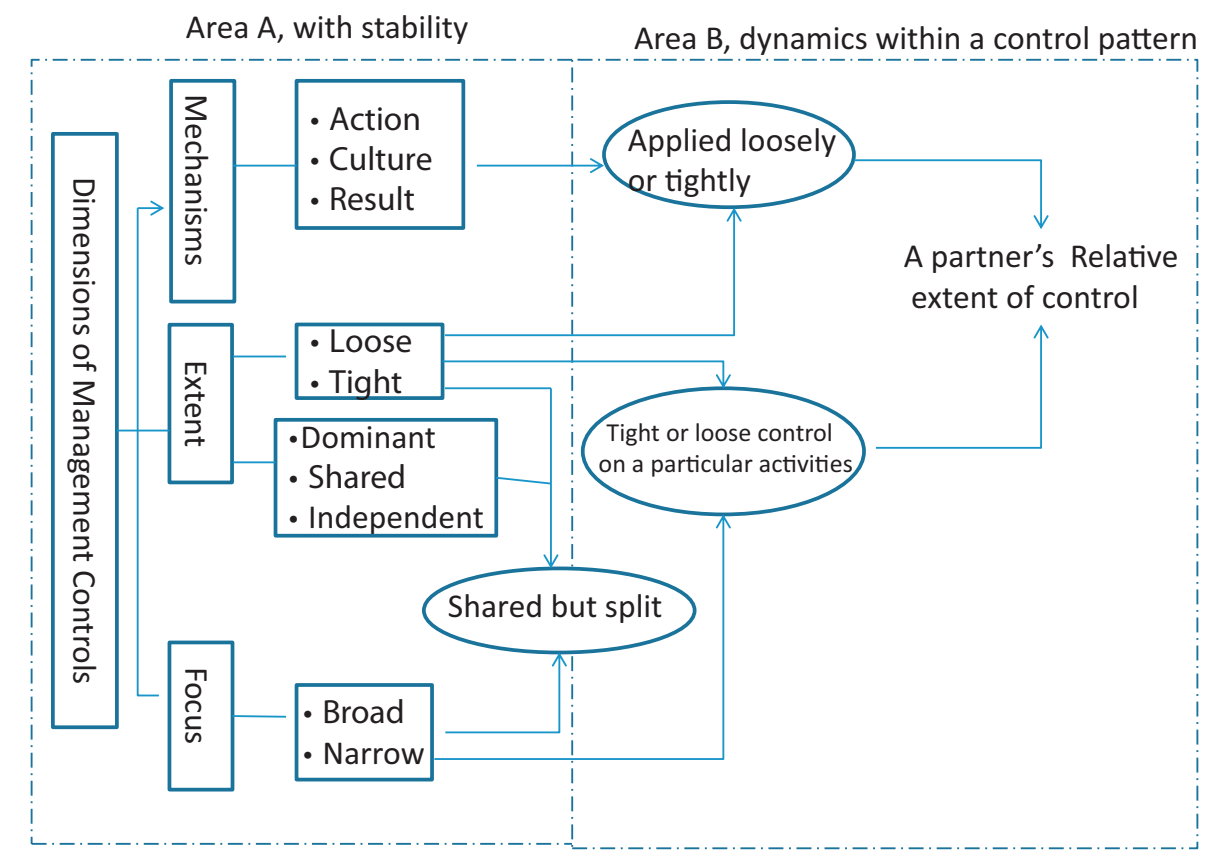

Fig. 3. Framework of control dimensions, inter-relationships, and dynamics.

parents remained unchanged. We throw light on how stability and change is balanced in dynamic environments.

\subsubsection{Controls in human resources management}

JT prefers dominant control in all areas, including in human resource management, which is generally regarded as an area in which a local parent has expertise. The following examples offer evidence of JT's dominant position at the earlier stage of YQJT: (1) YQJT gives priority to new graduates in its recruitment because inexperienced workers are likely to accept JT's management philosophy more easily. (2) Salaries paid to frontline workers were relatively low because JT was focusing its efforts on benefiting from lower labour costs. "We were the targets of head-hunters for quite a while, because our workers were well trained but been paid less than those in other Western-Chinese JVs," reported the Chinese financial manager. (3) There was no punishment in YQJT based on JT's expectations of loyalty in return for "life-long employment." However, circumstances have gradually changed in recent years. Salaries have been raised to competitive levels; some punishments, such as warnings, fines and redundancies, have been introduced. Chinese managers regard such changes as a victory in their fight for control. According to the interviewed Chinese managers, they "have fought very hard for these changes. Now [we] are working together with [our] Japanese colleagues on these issues and the Japanese colleagues do listen to [us]."

\subsubsection{Controls in design and marketing of new products}

YQJT established its Research and Development Department (R\&D) in 2008. R\&D is under the control of both parents and innovation patents belong to YQJT. In contrast to JT's dominant control on the introduction of new models and its "face-lift" of existing models before 2008, YQJT is now in charge of the face-lift of existing models; preferences expressed in the Chinese market are becoming an important consideration in introducing new products. It is expected that YQJT's R\&D will be directed more towards introduction of new models in future.

This new emphasis strengthens YQ's control in technology areas and satisfies their need for learning, while also being desirable to JT. JT is not particularly satisfied with its performance in the Chinese market in terms of market share, according to remarks made by a JT executive. This disappointment as regards market share is interpreted as that JT's production and management system does not fit well with Chinese culture. For example, while JT is proud of its operation procedure of "accepting orders, then planning manufacturing," Chinese customers cannot accept that they have to wait months for ordered cars. "We should put more efforts on understanding China, understanding how Chinese people think," reflected the Japanese planning manager.

Evolutionary changes in the extent of control over specific activities mediated the relative extent of control between two parents and narrowed the gap between the overall control extents of the two parents in the case company, as shown by the dotted arrows in the last column of Fig. 2. Approval of these changes in management controls by both parents provides empirical evidence for the argument put forward by previous studies that IJVs need to reconfigure over time to ensure stability and overall performance (e.g. Gray and Yan, 1992; Hamilton and Singh, 1991).

We argue further that the shared but split management style fits well into a dynamic commercial environment. Our case study shows, contrary to the findings of previous studies (e.g. Killing, 1983), that while the importance of the Chinese market, Chinese government policy in respect 
of certain industries, and local knowledge work together to give local companies greater bargaining power, shared management may nevertheless be preferred by local parents. Foreign-parent dominant management may not be desirable for local parents, especially for large state-owned firms, but it may not be desirable for foreign parents either, because such an arrangement potentially hampers IJVs benefiting from the knowledge and management expertise of local parents. JT's willingness to shift control to YQ in certain areas empirically supports this point. In this respect, our findings are consistent with those of Beamish (1988, 1993) and Yan and Gray (1994), who suggest the preference of a shared management style for IJVs in less developed countries.

The shared-but-split style reflects both parents' strategic positions, provides each with control access to the entire range of activities, and at the same time ensures that they can play to their strengths in a manner that is important for the success of the IJV. More importantly still, such a style offers a structure that allows evolutionary adaptation in managerial controls as a means of reflecting external and internal environment changes, while maintaining structural stability, which is crucial for effective IJVs. The case demonstrates how the extent of control on the part of the Chinese parent has increased, and how the balance between maintaining structural stability and allowing evolutionary adaption is achieved. This feature is depicted by the model cutting across areas A and B in Fig. 3. The observation of shared but split control style provides further supporting evidence to Dekker (2004), who argues that an important purpose of IJV's governance structure is to guarantee stability and continuity of the IJV to cope with uncertainty about organisational management.

These findings are further synthesised in Fig. 3. What we have found in relation to area $B$ is that how management controls can be reshaped within a control pattern. The evolutionary changes are achieved by means of adjustments of control extent over a particular activity and the relative tightness of a mechanism, and eventually those changes adjust the relevant extent of control of a parent. The shared but split control model provides such a structure that allows evolutionary adaptation but maintains structural stability in parents' management control over its IJV.

\section{Conclusion}

Focusing on the post-formation stage of a Sino-Japanese automotive joint venture, this study provides in-depth observation of the interrelationships and dynamics of the three control dimensions, namely mechanisms, focus, and extent. The findings shed light on the characteristics of management controls exercised by each parent, and how they evolve during IJV operation.

The significance of the study lies in the findings of how the characteristics of controls evolved as the environments change and how the balance between maintaining structural stability and allowing evolutionary adaptation is achieved. Although it is commonly accepted that managing IJVs formed in emerging economies is particularly challenging due to turbulent political and economic environments, there is no previous study investigating how an IJV manages the tension between stability and change. The present study offers the first observation on how parents may adjust the control extent they exercise over specific activities or the tightness of a control mechanism in order to reflect environmental changes without unsettling the overall control structure.

In the case company, the overall management control structure is established at the formation stage, represented by a shared but split control style. This identified control style, as a supplement to previous descriptions of management style in IJVs, is featured with a broad control focus over the entire range of activities shared by both parents but only tight control over certain number of areas for each. Particular control mechanisms are chosen to achieve each parent's control focus and extent, such as action control (BoD and personnel appointment) and culture control (adopting similar production and management systems, and mentoring and training) for JT, and the same action control plus result control (manager performance incentives and budgeting) for YQ. The study identified a tighter control possessed by JT regardless the 50:50 equity structure. However, this control structure featuring un-even control extent between two parents has been challenged at the operation stage, and the adaptation in management controls is needed to reflect the changing environments. On the one hand, the more important Chinese market grants the local partner a stronger position and also makes local knowledge a more significant contribution to the success of the IJV; and on the other hand, although JT, as an overseas partner, insists on adhering to their own management philosophy, they encounter a culture clash on customer satisfaction and employees motivation. As a result of continuous competition and collaboration between the executives and managers from both parents in IJV operation, YQ obtains an increased control extent in the areas of HR management and new products design and marketing, and the gap between two parents' overall control extent is narrowed down. Here the shared but split control style provides a structure within which the balance between stability and change is achieved. In this respect, the finding further advances our understanding of how evolutionary adaptation in management controls could be used as a means to reflect environment changes while maintaining structural stability. Our study helps to remedy a significant gap in the available JIV research, and the findings enhance our understanding of the nature of IJV controls.

The recognition of shared management through a broad control focus employed by both parents extends the conclusion reached by previous studies supporting the preference of shared management style for IJVs in less developed countries. The study also evidences the extending of bargaining from the formation to operation stage of the IJV, which brings elements of support and challenge into the relationship between managers from the two parent companies. As there is no sign so far of relaxing the restrictions on the foreign partner's equity share from the Chinese government, 50:50 equity IJV in China, particularly in the restricted industries such as automotive, will remain as a common joint venture form. In this case, the challenge 
is how a partner could use management controls as a means to protect their input resources and ensure the achievement of the strategic objectives while both collaborative and competitive forces are simultaneously at work within the IJV. The findings in this respect have practical implications as regards managing IJVs, particularly for those formed between partners from developed and developing economies, namely, China.

As a study in the context of IJVs involving Chinese parents, our findings have also presented a different picture of the Chinese partners' control style. We observed a broad control focus from the Chinese parent, contradicting the evidence in the literature. The intention of obtaining control access over the entire range of activities indicates strong desire for profitability. Even learning remains as an important objective, its scope has extended from just technologies to including management and production systems.

Based on the observed characteristics of management controls in the case company, the paper presents a refined theoretical model (Fig. 3), in which the interrelationships between three primary control dimensions and their dynamics are depicted. It may provide theoretical guidance for future research in IJV controls. More specifically, the model provides a systematic way to assess a parent's relative extent of control over IJVs, which may be used in control-performance relationship research to improve the measure of control in such studies. The empirical evidence that the Japanese parent possess the tighter control over the IJV while both parents have equal equity shares provides additional evidence on the debates of using equity structure as equivalent to management control.

While our study helps to remedy a significant gap in the available research literature, it is limited to a single case study. It would accordingly be useful to replicate the study in other IJVs, with similar or different contexts, in order to confirm our findings. While previous studies have focused on trust between partners, further research on trust and learning between expatriate managers, particularly, on how management control mechanisms could be used to facilitate collaboration in a supportive yet challenging environment, would further enhance our understanding of the effectiveness of controls in IJVs.

\section{Acknowledgements}

The authors are grateful for the funding support of CIMA General Charitable Trust and the National Nature
Science Foundation of China on this project. The helpful comments of the following are gratefully acknowledged: Christopher Chapman, Richard Croucher, Paul Gooderham, Richard Macve, Kenneth Merchant, Jason Xiao, and the conference participants at Management Accounting Research Group's conference (2009), the "Management Accounting and Strategic Alliances" conference at LSE (2010), and 11th International Symposium on Empirical Accounting Research in China (2012). We also thank the editor and the reviewers for their helpful comments and suggestions.

\section{Appendix A.}

Interview informants and questions.

\begin{tabular}{lll}
\hline & Interviews & \\
\cline { 2 - 3 } & Chinese YQ & Japanese JT \\
\hline At headquarters & $\begin{array}{l}\text { Executive in charge of } \\
\text { the co-operation with } \\
\text { JT (1) }\end{array}$ & $\begin{array}{l}\text { Managing director } \\
(1)\end{array}$ \\
& & Finance director (1) \\
& & Planning manager \\
At the IJV (YQJT) & $\begin{array}{l}\text { Deputy general } \\
\text { manager of finance (3) }\end{array}$ & feneral manager of \\
& fash flow manager (1) & Cost manager (1) \\
& $\begin{array}{l}\text { Deputy director of R\&D } \\
\text { (1) }\end{array}$ & Administrative \\
& manager (1) \\
& $\begin{array}{l}\text { Penior engineer in } \\
\text { Department (1) }\end{array}$ & \\
& Two senior engineer in & \\
Technology & \\
Department (1 for & \\
each) & \\
\hline
\end{tabular}

\section{Interview Guide (adapted for informants as appropriate)}

The resources contributed to the joint venture from both parent companies, any changes since the establishment of the IIV.

The strategic objectives set for the joint venture and the extent of achievement, any changes since the establishment of the IJV.

The form and the frequency of communications between the joint venture and the parent company, any changes since the establishment of the IJV. The control mechanisms (e.g. delegation of decision making authority, expatriate staff, training, budgeting) adopted by the parent companies to ensure the achievement of the strategic objectives, any changes since the establishment of the IJV.

Your opinion regarding the effectiveness of these control mechanisms any changes since the establishment of the IJV.

Your working experience in the IJVT and the factors contributed to the effectiveness or ineffectiveness of cooperation between your company and the partner, any changes since the establishment of the IJV.

a The number after each informant indicates the times of interview. 


\section{Appendix B.}

The profile of YQJT and its two parent companies.

\begin{tabular}{|c|c|c|c|c|c|c|}
\hline & Establishment & Capital & Corporate governance & Employees & Annual production (000 cars) & $\begin{array}{l}\text { Worldwide } \\
\text { presence }\end{array}$ \\
\hline Chinese parent -YQ & 1956 & 213 billion RMB & $\begin{array}{l}\text { Publicly traded on } \\
\text { Tokyo, New York and } \\
\text { London Stock Exchange }\end{array}$ & 325,905 & 7450 & $\begin{array}{l}28 \text { wholly owned } \\
\text { and } 18 \text { partially } \\
\text { owned } \\
\text { subsidiaries, } \\
\text { including two IJVs, } \\
\text { located in } 17 \text { cities } \\
\text { in China }\end{array}$ \\
\hline Japanese parent - JT & 1937 & $\$ 128,201$ million & $\begin{array}{l}\text { Publicly traded on } \\
\text { Shengchen and } \\
\text { Shanghai Stock } \\
\text { Exchange }\end{array}$ & 120,000 & 2600 & $\begin{array}{l}\text { Has factories in } \\
\text { most parts of the } \\
\text { world }\end{array}$ \\
\hline The IJV - YQJT & 2003 & \$408 million & $\begin{array}{l}\text { IJV, 50-50 owned by } \\
\text { YQ and JT }\end{array}$ & 12,000 & 420 & $\begin{array}{l}\text { The sales ranked as } \\
9 \text { in } 2011 \text { in } \\
\text { Chinese } \\
\text { passenger-car } \\
\text { market }\end{array}$ \\
\hline
\end{tabular}

\section{References}

Beamish, P.W., 1988. Multinational joint venture in developing countries. Routledge, New York.

Beamish, P.W., 1993. Characteristics of joint ventures in the People's Republic of China. Journal of International Marketing 22, 63-78.

Bjorkman, I., Lu, Y., 2001. Institutionalization and bargaining power explanations of HRM practices in international joint ventures - the case of Chinese-Western joint ventures. Organizations Studies 22/23, 491-512.

Calantone, R.J., Zhao, Y.S., 2000. Joint venture in China: a comparative study of Japanese, Korean and US partners. Journal of International Marketing 9 (1), 1-23.

Chalos, P., O'Conner, N.G., 2004. Determinants of the use of various control mechanisms in US-Chinese joint ventures. Accounting, Organizations and Society 29, 591-608.

Chalos, P., O'Conner, N.G., 2005. The perceived effect of accounting controls on US-Chinese joint venture transaction costs and performance. Journal of International Accounting Research 4 (2), 53-73.

Chen, D., Paik, Y., Park, S.H., 2010. Host country policies and MNE management control in IJVs: Evidence from China. Journal of International Business Studies 41 (3), 526-537.

Child, J., Yan, Y., 2003. Predicting the performance of international joint ventures: an investigation in China. Journal of Management Studies 40 (2), 283-319.

Cooper, H., Johnson, I., 26-28 May 2000. Congress's voteprimes firms in U.S. to boost China deals. Asian Wall Street Journal. pp. 1, 7.

Dekker, H., 2004. Control of inter-organizational relationships: evidence on appropriation concerns and coordination requirements. Accounting, Organizations and Society 29, 27-49.

Geringer, J.M., 1986. Criteria for selecting partners for joint ventures in industrialized market economies. Ph.D. dissertation, University of Washington, Seattle.

Geringer, J.M., Hebert, L., 1989. Control and performance of international joint ventures. Journal of International Business Studies 20 (2), 235-254.

Glaister, P.W., Buckley, P.J., 1994. UK international joint ventures: an analysis of pattern and distribution. British Journal of Management 5, 33-51.

Gray, B., Yan, A., 1997. Formation and evolution of international joint ventures: examples from US/Chinese partnerships. In: Beamish, P., Killingn, P.(Eds.), Global Perspectives on Cooperative Strategies: Asian Perspectives. The New Lexington Press, San Francisco, pp. 57-88.

Gray, B., Yan, A., 1992. A negotiations model of joint venture formation, structure and performance: implications for global management. Advances in International Comparative Management 7, 41-75.

Groot, L.C.M., Merchant, K.A., 2000. Control of international joint ventures. Accounting, Organizations and Society 25, 579-607.

Hamilton, W., Singh, H., 1991. Strategic alliances in technological innovation: cooperation in biotechnology. The Journal of High Technology Management Research 2 (2), 211-221.

Kamminga, P.E., Van der Meer-Kooistra, J.V., 2007. Management control patterns in joint venture relationships: a model and an exploratory study. Accounting, Organizations and Society 32, 131-154.
Killing, J.P., 1983. Strategies for Joint Venture Success. Croom Helm, Kent. Kopp, R., 1994. International human resource policies and practices in Japanese, European, and United States multinationals. Human Resource Management 33 (4), 581-599.

Li, P., Tang, G., Okano, H., Gao, C., 2011. Management controls in automotive international joint ventures involving Chinese parent companies. Chartered Institute of Management Accounting, Research Executive Summary Series. 7(9), 1-8. http://www.cimaglobal.com/pingli

Luo, Y., Shenkar, O., Nyaw, M.-K., 2001. A dual parent perspective on control and performance in international joint ventures: lessons from a developing economy. Journal of International Business Studies 32 (1), 41-58.

Merchant, K.A., 1998. Modern Management Control Systems. Prentice Hall, Upper Saddle River, NJ.

Mjoen, H., Tallman, S., 1997. Control and performance in international joint ventures. Organization Science 8 (3), 257-273.

Nam, K.-M., 2011. Learning through the international joint venture: lessons from the experience of China's automotive sector. Industrial and Corporate Change 20 (3), 855-907.

Newman, W.H., 1992. Focused joint ventures in transforming economies. Academy of Management Executive 6 (1), 67-75.

Ouchi, W.G., 1977. The relationship between organizational structure and organizational control. Administrative Science Quarterly 22, 92-112.

Park, S.H., 1996. Managing an interorganizational network: a framework of the institutional mechanism for network control. Organization Studies 17 (5), 795-824.

Parkhe, A., 1993. Strategic alliance structuring: a game theoretic and transaction cost examination of interfirm cooperation. Academy of Management Journal 36 (4), 794-829.

Schaan, J.L. 1983. Parent control and joint venture success: the case of Mexico. Doctoral dissertation, University of Western Ontario.

Scott, W.R., 1987. Organizations: Rational, Natural, and Open Systems. Prentice-Hall, Englewood Cliffs, NJ.

Stinchcombe, A.L., 1965. Social structure and organizations. In: March, J.g. (Ed.), Handbook of Organizations. Rand McNally, Chicago, pp. $142-193$.

Tallman, S.B., Shenkar, O., 1994. A managerial decision model of international cooperative venture formation. Journal of International Business Studies 69, 91-113.

Xia, J., Tan, J., Tan, D., 2008. Mimetic entry and bandwagon effect: the rise and decline of international equity joint venture in China. Strategic Management Journal 29, 195-217.

Yan, A., Gray, B., 2001. Antecedents and effects of parent control in international joint ventures. Journal of Management Studies 38 (3), 393-416.

Yan, A., Gray, B., 1994. Bargaining power, management control, and performance in United States-China joint ventures: a comparative case study. Academy of Management Journal 37 (6), 1478-1517.

Yan, A., 1998. Structural stability and reconfiguration of international joint ventures. Journal of International Business Studies 29 (4), 773-795.

Yin, R.K., 2009. Case Study Research: Design and Methods, 4th ed. Sage Publications, Los Angeles. 